\title{
The Future of the Brain
}

\author{
Edited by Gary Marcus and Jeremy Freeman
}

\author{
Hardbound, 240x160 mm, 304 pages, ISBN : 9780691162768; Princeton University Press, 2015 \\ press.princeton.edu \\ Anatomy 2015;9(1):48 @2015 Turkish Society of Anatomy and Clinical Anatomy (TSACA)
}

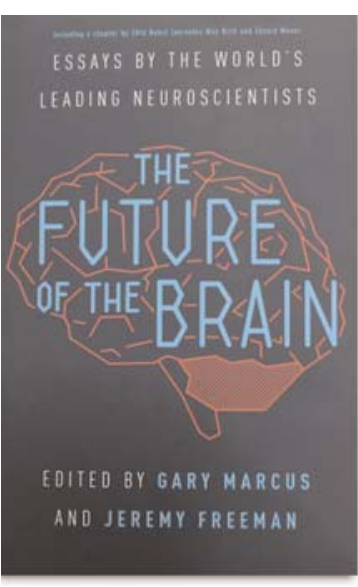

This is an exciting era in neuroscience. As the editors of this book have stated, although the field has existed for two centuries, progress to understand the complexity of the brain has in many ways been slow. With the advance of new technologies, this is now changing fast. Noninvasive forms of brain imaging such as functional magnetic resonance imaging, revolutionary techniques such as optogenetics and CLARITY are now giving an enormous amount of new data at an unprecedented level of detail for the nervous system.

This is an edited book by Gary Marcus and Jeremy Freeman, 'The Future of the Brain' (Princeton University Press, 2015). Gary Marcus is professor of psychology and neural science at New York University, visitor at the Allen Institute for Brain Science, and a best-selling author. Jeremy Freeman is a neuroscientist at the Howard Hughes Medical Institute's Janelia Farm Research Campus.

The book brings together 22 original essays by the world's leading neuroscientists, philosophers, and psychologists such as Christof Koch, George Church, Olaf Sporms, and the 2014 Nobel laureates May-Britt and Edward Moser. Essays cover mapping the brain including building atlases on the brain and the 'Connectome Project', computation in neuroscience, simulating the brain, the neurobiology of language, consciousness, evolution, computational brain, and neurotechnology. The final chapter, 'Neuroscience in 2064. A look at the last century', by Christof Koch and Gary Marcus describes the advances in neuroscience starting from the 1963 Nobel Prize awarded to Alan Hodgkin and Andrew Huxley for describing the sodium and potassium membrane currents that power the electrical impulse, the action potential, as it travels along the axon. Then, it comes to 2014 when neuroscience becomes big science, with molecular advances, Eric Kandel's Nobel Prize-winning work to the 1990s, and MRI refined to image the functional architecture of the active brain certainly contributing to cognitive neuroscience to a great extent. It also covers opto- and pharmaco-genetics that control defined events in defined cell types at defined times, contributing to the understanding of the brain.

This is definitely a very captivating book that provides a profound, appealing view into the most exciting advances in neuroscience. It shows how immense technological advances promise rapid and profound discoveries in neuroscience, and contribute to our understanding of the brain, on what we do and don't know about the human brain--and predictions on what may come next.
Review by Gülgün Şengül
Editor-in-Chief, "Anatomy”
Department of Anatomy,
Faculty of Medicine, Ege University,
Bornova, 35100, Izmir, Turkey
e-mail: gulgun.sengul@gmail.com

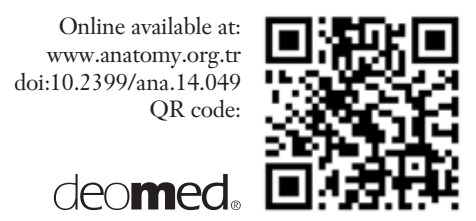

This is an open access article distributed under the terms of the Creative Commons Attribution-NonCommercial-NoDerivs 3.0 Unported (CC BY-NCND3.0) Licence (http://creativecommons.org/licenses/by-nc-nd/3.0/) which permits unrestricted noncommercial use, distribution, and reproduction in any medium, provided the original work is properly cited. Please cite this article as: Şengül G. Book Review: the Future of the Brain. Edited by Gary Marcus and Jeremy Freeman. Anatomy 2015;9(1):48. 